\title{
Explicit and implicit corporate social responsibility: Differences in the approach to stakeholder engagement activities of U.S. and Japanese companies
}

\author{
Kamalesh Kumar ${ }^{1}$ | Giacomo Boesso ${ }^{2}$ (D) | Rishtee Batra ${ }^{3}$ | Jun Yao ${ }^{4}$
}

${ }^{1}$ College of Business, University of MichiganDearborn, Dearborn, Michigan

${ }^{2}$ Department of Economics and Management, University of Padova, Padua, Italy

${ }^{3}$ Haub School of Business, St. Joseph's University, Philadelphia, Pennsylvania

${ }^{4}$ School of Commerce, Meiji University, Tokyo, Japan

\section{Correspondence}

Giacomo Boesso, Department of Economics and Management, University of Padova,

Padua, Italy.

Email: giacomo.boesso@unipd.it

\begin{abstract}
This study uses the theoretical frameworks of institutional theory and comparative capitalism to demonstrate how cross-cultural differences in national institutional frameworks are related to differences in the meaning and the nature of corporate social responsibility (CSR) and, as a result, how they create different incentives and opportunities for companies to engage in stakeholder management activities. More specifically, we draw upon the framework of "explicit" and "implicit" CSRs to investigate whether and how stakeholder management practices and programs differ between the United States and Japan. We first develop and validate a Stakeholder Engagement Activities (SEAs) scale, designed assess differences in the approach (explicit or implicit) that companies use to address a variety of common SEAs. Then we analyze data and present the results of surveys collected from 227 companies in the United States and Japan. We find that although the SEAs of American companies are characterized by strong "explicit CSR," in contrast, the SEAs of Japanese companies exhibit strong "implicit CSR." In the discussion that follows, we attribute these distinctions in the SEAs to differences in the configuration of political, economic, and market mechanisms in each country. The findings of this study contribute to a more nuanced understanding of the differences in prevailing CSR practices of American and Japanese companies than noted by previous researchers. From a practitioner's perspective, the findings of this study reveal that despite the global nature of CSR, stakeholder management practices are both interpreted and operationalized differently due to differences in national institutional frameworks.
\end{abstract}

\section{KEYWORDS}

cross-cultural CSR, CSR in the United States and Japan, institutional theory and CSR, stakeholder engagement activities, stakeholder management, stakeholder management in the United States and Japan

\section{1 | INTRODUCTION}

Past research on corporate social responsibility (CSR) and stakeholder management shows that although more companies across the world have begun to adopt CSR practices, companies in certain countries show a much greater propensity to engage in CSR practices than others (Freeman \& Hasnaoui, 2011; Gjølberg, 2009; Ho, Wang, \& Vitell, 2012). In particular, comparative research on CSR practices in the United States and Japan has identified remarkable differences in the prevalence of CSR policies and practices enacted by American 
and Japanese companies (Fukukawa \& Teramoto, 2009; Matten \& Moon, 2008). As a result, some have characterized Japan as somehow lagging in its development and adoption of CSR practices. The purpose of the present study is to further investigate whether and how CSR practices and programs differ between the United States and Japan and to better understand the nature of and possible reasons for these differences.

We start by first summarizing findings about cross-national differences in the nature of CSR based on the theoretical frameworks of institutional theory (Aguilera \& Jackson, 2003) and comparative capitalism (Soskice \& Hall, 2001). Next, we draw upon the work of Matten and Moon (2008), who argue that the CSR policies, programs, and practices enacted by companies in a country are contextualized by the national institutional frameworks and reflect wider policy arrangements that exist in a country. They distinguish between two distinct approaches to CSR-an "explicit" CSR approach and an "implicit" CSR approach. The explicit CSR approach, more prevalent in liberal market economies (LMEs), is one in which companies use their discretion to in firm-specific CSR practices. In contrast, an implicit CSR approach, more prevalent in coordinated market economies (CMEs), is characterized by which CSR practices that are collectively and implicitly addressed by companies in their day-to-day business activities.

We utilize the notion of implicit and explicit CSRs, to explain the resulting differences in SEAs in the context of this study. In particular, we investigate how differences in the national, business, and economic institutional contexts of Japan and the United States create different incentives and opportunities for companies, resulting in very different approaches to the issues associated with CSR and stakeholder management. We first develop and validate a Stakeholder Engagement Activities (SEAs) scale designed to focus on the different ways in which companies approach and address a range of common SEAs-explicitly or implicitly. Next, we analyze and present the results of data collected from 229 companies in the United States and Japan. We first conducted a factor analysis order to identify differences in companies' approaches to managing SEAs. Next, we utilized the two factors that were extracted from the results of factor analysis (which were labelled as "explicit CSR" and "implicit CSR") and using an analysis of variance (ANOVA), we examined the difference between the SEAs of the American and Japanese organizations. Finally, to understand the nuanced differences in the SEAs of the American and Japanese companies, we once again relied upon an ANOVA to examine the differences in terms of each individual item included in the two factors -explicit CSR and implicit CSR. Finally, we interpret these findings and discuss both their theoretical and substantive implications.

Although existing research provides rich descriptions of the differences in CSR practices between the United States and Japan, it has not examined these differences from the underlying perspective of the institutional contexts in which companies operate. The present paper contributes to this stream of literature by operationalizing and empirically validating the framework of implicit and explicit CSRs proposed by Matten and Moon (2008). Furthermore, we contribute to the extant literature on cross-cultural CSR by demonstrating that cross- cultural differences in CSR and stakeholder management practices can be attributed to differences in the configuration of countryspecific social, political, economic, and market mechanisms.

\section{I INSTITUTIONAL THEORY, COMPARATIVE CAPITALISM, AND CSR}

Institutional theory focuses on differences in the configuration and coordinating mechanism of institutions, including public and private regulations, market versus hierarchies, state participation in businesses, governmental interventions, and social networks and associations. Past research show that a country's institutional arrangements often act as antecedents of CSR and are in fact strong motivators for CSR engagement and stakeholder management (Campbell, 2007). Scholars have also argued that contemporary institutional theory (Aguilera \& Jackson, 2003) is particularly useful for understanding cross-national differences in CSR and stakeholder management practices (Ben-Amar \& Chelli, 2018; Campbell, 2007; Ho et al., 2012; Tempel \& Walgenbach, 2007).

Based on institutional differences in and coordination mechanisms related to industrial relations, vocational training and education, corporate governance, interfirm relationships, and relationship with employees, Soskice and Hall (2001) have categorized countries as LMEs (e.g., the United States, the United Kingdom, Australia, and Canada) and CMEs (e.g., Germany, Scandinavian countries, Japan, and Austria). LMEs and CMEs have systematic differences in their markets, resulting in different business systems and institutional contexts. With respect to CSR and stakeholder engagement, CSR strategies are chosen by individual companies; these choices are framed in the broader social, political, and economic institutional contexts of the country (Matten \& Moon, 2008).

At the core, CSR consists of policies and practices with regard to business responsibilities for wider societal good. Yet, to the extent that the CSR of a company remains contextualized by the national institutional framework, one should find differences in how such business responsibilities are manifested and enacted. As such, Matten and Moon (2008) have conceptualized cross-national differences resulting in explicit and implicit CSRs, each stemming from countries with distinct national business systems and institutional contexts.

Explicit CSR involves enacting company-specific CSR policies and programs of social interest and explicitly articulating these claims from various stakeholder groups. It consists of voluntary initiatives in which companies combine both societal and business value and address issues that are perceived as part of a broader social responsibility. Such CSR initiatives rest largely on the discretion of individual companies, rather than governmental authority or institutional demands (Matten \& Moon, 2008); there is no societal or government mandate as such that specifies the nature or extent of CSR appropriateness. Examples of explicit CSR can be found in the voluntary programs and strategies of numerous American companies, whose CSR activities combine both social and corporate motives (Matten \& Moon, 2008). Take, for example, the recent voluntary CSR programs of Microsoft 
regarding global education or the launch of the Starbucks Foundation -which not only provides social support but also improves service and operational efficiency. Or consider Google's corporate effort to conserve electricity, which not only reaps environmental benefits but also improves their efficiency, as data centers have drastically reduced their power requirements (Autodesk.com, 2018).

Implicit CSR, on the other hand, is based upon the expectations of a company's role "within the wider formal and informal institutions for society's interests and concerns" (Matten \& Moon, 2008, p. 409). As a result, implicit CSR is manifested in mandatory policies and practices for companies that address a variety of stakeholder issues. Additionally, in contrast to explicit CSR, these policies are decided upon collectively rather than by individual companies. Although companies with an implicit CSR approach may have policies and programs similar to those with an explicit CSR approach, the initiatives in implicit CSR are not company specific, discretionary, or voluntary. Rather, they are the result of a collective deliberation of the players involved in the institutional contexts of the company. Implicit CSR occurs in the form of codified norms, rules, and laws that are not conventionally described explicitly as "CSR" (Matten \& Moon, 2008). Examples include providing health insurance, pensions, and employee benefits. Implicit CSR also includes pursuing collective interests through national business associations, embedded relations with wide set of stakeholders, self-regulatory and voluntary initiatives, and the Japanese keiretsu or the Korean chaebol. In each of these cases, companies do not claim distinct ownership of the practices; they act in socially responsible ways and comply with customary societal. Table 1

TABLE 1 Summary comparison of the differences between "implicit" and "explicit" CSRs

Explicit CSR
Corporate policies, programs, and
strategies are voluntarily
enacted by companies and
addresses issues perceived to be
important for CSR of the
company.

CSR policies and programs are motivated by company's perception and assessment of the demands and pressures of

Companies make distinctive claims over CSR programs and policies and describe their activities this way.

Companies make claims about their individual CSR activities and programs. different stakeholder groups.

\section{Implicit CSR}

CSR policies, programs, and strategies are not the outcome of deliberate corporate decisions but are based on norms, values, and rules governing corporate role within the wider formal and informal societal interests and concerns.

CSR policies and programs are collectively motivated and result in both mandatory and customary requirements for companies to address stakeholder issues.

CSR is implied in systems of organizational responsibilities, and companies are involved in deciding CSR programs and policies and do not articulate their own versions of them.

Companies have little opportunity or incentive to take explicit responsibility for CSR activities or programs
Adapted from Matten and Moon (2008) provides a comparison of the differences between the implicit and explicit CSR approaches.

Based on the review of the existing literature, it seems as if although CSR may be considered strategically significant in organizations around the world, the principles behind its adoption, the manner in which it is articulated, and the policies and practices that are pursued are embedded in the economic, political, and social environments of a country. Given that such differences exist, it seems logical that there would also exist cross-national differences in the way different countries express and pursue CSR (Matten \& Moon, 2008).

\section{I HOW AND WHY CSR PRACTICES MAY VARY IN THE UNITED STATES AND JAPAN: RESEARCH PROPOSITION}

As mentioned earlier, based on the distinction between the attributes associated with an implicit CSR versus an explicit CSR, the CSR policies and practices of American companies are "embedded in a system that leaves more incentive and opportunity for corporations to take comparatively explicit responsibility" (Matten and Moon, 2008, p. 409). In addition, American companies are generally more explicit in articulating their CSR programs, constituting an explicit CSR approach. On the other hand, in Japan, Korea, and many European countries, CSR is implied in a wider societal responsibility, leaving little opportunities and incentives for companies to take explicit responsibility. The more subtle Japanese approach to CSR, generally void of companyspecific claims of socially responsible behaviors, is more congruent with the implicit CSR approach. One commonly offered explanation for this difference is that companies in general Asian companies, particularly Japan, have only recently begun to adopt broader social responsibilities in their corporate agenda (Lee, Ha-Brookshire, \& Chow, 2018; Chappel \& Moon, 2005; Brucksch \& Grünschloß, 2009). However, a closer review of the business practices of Japanese companies reveals that socially responsible business practices have always been and continue to be part of their day-to-day business activities. The difference, however, is that the CSR practices are enacted in ways that reflect wider policy arrangements and they tend to be implicit, so that claims of socially responsible corporate behaviors are not company specific but are instead commonplace (and expected) in most organizations.

This raises the question as to why American companies show a far greater propensity to engage in discretionary and company-specific CSR programs, whereas Japanese companies, even when enacting CSR programs and policies, continue to be more subtle and indirect about their CSR actions. On the basis of the research frameworks of institutional theory and variety of capitalism, we argue that differences in CSR practices between the United States and Japan are due to differences in the economic, social, and governmental institutional contexts that influence the "national business systems" (Whitley, 1998) and corporate governance. As noted earlier, the comparative capitalism approach distinguishes LMEs such as the United States from CMEs such as Japan. Bridging these two frameworks together, 
we further investigate whether differences in the national business systems and institutional contexts of these two countries might help explain the divergent ways in which American and Japanese corporations interpret, express, and pursue CSR.

The nature of CSR in the United States is embedded in a system that leaves CSR at the discretion of corporations, each of which identify company-specific opportunities for socially responsible behaviors. The corporate social policies and programs enacted by each company are voluntary and are motivated by the perceived expectations of different stakeholders of the company. In pursuing the programs and strategies associated with this explicit approach to CSR, companies combine both social and business value propositions (Porter \& Kramer, 2006). In addition, American companies also explicitly communicate claims regarding their socially responsible behaviors to their stakeholders. The institutional context that exists in an LME such as the United States provides a greater incentive for companies to undertake more explicit CSR initiatives. Although many American companies may describe CSR as part of their strategic values, the social involvement of companies is largely motivated through voluntary engagements of different stakeholder groups. These stakeholder groups also pursue their own agendas as a credible way of protecting their interests within a firm. In this context, although compliance with existing CSR laws is necessary, engagement in CSR initiatives is also seen as a strategically important move for the overall survival and growth of a business.

In comparison, the national business system in Japan is characterized by high public ownership, patriarchal and long-term employment, and coordination and control systems that are based on long-term partnership (Matten \& Moon, 2008). In such CMEs, CSR is recognized as "the company's role within the wider formal and informal institutions for society's interests and concerns," and its policies and programs are "motivated by the societal consensus on the legitimate role and contributions of corporations" (Matten \& Moon, 2008, p. 410). In the Japanese context, CSR is interpreted as "those corporate principles and policies-keiei rinen or hoshin" (Fukukawa \& Teramoto, 2009 , p. 138) that have long been in practice and have always influenced corporate activities (Hosoda \& Suzuki, 2015; Lee, Park, Song, $\&$ Yook, 2016). The policies associated with implicit CSR result from societal expectations of the corporation's role in society. National institutions encourage, mandate, and even legally require companies to engage in corporate social obligations in collective rather than individual terms (Kobayashi, Eweje, \& Tappin, 2018; Nakano, 2007). Although representatives of various companies are often involved in formulating these CSR policies, companies that practice implicit CSR do not make company-specific claims in communicating their CSR policies and programs. In other words, CSR policies are not seen as a choice made by individual companies but rather are expected to be universally adopted by all companies for the greater good of society.

Given the distinctions outlined above, there is reason to expect that although the CSR activities of American companies will be characterized by strong explicit CSR, the CSR activities of Japanese companies will exhibit strong implicit CSR.

\section{4 | METHODOLOGY}

\section{1 | Sample and data collection}

Data for this study come from a larger database that was collected by the authors to study various cross-national differences in CSR and stakeholder management practices during the years 2015 and 2016 (Kumar, Boesso, \& Yao, 2017). The sample for this study consisted of 227 companies, of which 119 were from Japan and 108 from the United States. In the United States, data were collected using an anonymous questionnaire administered to mid-level managers attending strategic management seminars. It was determined that all of these managers were in positions that allowed them to have an understanding about the CSR and stakeholder management practices of their organizations. In Japan, data were collected via mailed questionnaires that were translated into Japanese. The original English version of the questionnaire was translated into Japanese by the coauthor, who works in a university in Japan. The translation was double-checked by two Japanese natives-one being a professor of accounting and the other an employee of the Osaka Research Center for Industry and Economy. Both of these individuals were proficient in English and had good understanding of the concept of CSR.

In terms of demographic profile of the sample, $64 \%$ of the managers had 10 or more years of work experience, spanning seven different industries: industrial, pharmaceuticals, fashion, financial services, food, energy, and other services. Forty-seven percent of the managers worked in manufacturing organizations, $28 \%$ in service organizations, and the remaining in other mixed-activity organizations.

\section{2 | Operationalization and measurement of SEAs}

Our literature search revealed no established scale for measuring SEAs. A review of the extant literature (Aguinis \& Glavas, 2012; Taras, Steel, \& Kirkman, 2011) showed that the vast majority of the CSR studies (e.g., Choi \& Wang, 2009; Coombs \& Gilley, 2005; Graves \& Waddock, 1994; Hillman \& Keim, 2001; Johnson \& Greening, 1999; Kumar, Boesso, \& Michelon, 2016) have relied on databases such as Kinder, Lydenberg, Domini (KLD), the Fortune Index, or the Canadian Social Investment Database (CSID), all of which evaluate companies in terms of their engagement in and their ability to meet the demands of various stakeholder groups. Other studies (e.g., Boesso \& Kumar, 2009; Eweje \& Sakaki, 2015; Russo \& Tencati, 2009) simply asked the respondents whether or not (or to what extent) they engaged in a list of socially responsible behaviors related to various stakeholder groups.

Although using data or other proxy measures (such as corporate social disclosures/reports) from publicly available databases to assess the CSR activities offers the advantage of objectivity, it does not provide much insight into the approaches adopted by the companies in the performance of the CSR activities. Because the focus of the present study is to understand the differences in approaches to the CSR/SEAs (explicit vs. implicit) rather than merely the presence or 
absence of (or perhaps the extent of) SEAs, we chose to develop a multi-item SEA scale designed to measure whether a company's SEAs were performed explicitly or implicitly. Although developing a new scale does raise concerns related to the measurement of constructs, we took various precautions and performed validity and reliability tests to ensure its psychometric robustness.

We began the scale development process by creating a pool of 12 items that included common SEAs identified in the literature (Carroll, 1979; Porter \& Kramer, 2006), of which six items represented an explicit CSR approach and the other six items an implicit CSR approach. The SEA scale was designed to focus on the differences in the ways in which (explicitly or implicitly) companies approached and addressed a range of common stakeholder management activities. Because companies practicing implicit CSR might have policies and practices similar to companies practicing explicit CSR, the items included in the scale focused on two differentiating characteristics. The first novel aspect of the SEA scale was that it included questions assessing to what extent a company's discretion that was involved in the performance of the SEA, whether or not it was company initiated. Second, we also focused on the nature of the claim made in the SEA, whether or not it was company specific. In looking at the items presented in Appendix A, one can notice that items designed to measure explicit CSR are focused on company-specific measures and companyinitiated CSR activities, whereas that is not the case with items designed to measure implicit CSR.

\section{3 | Validity checks}

Although the items used to measure SEAs were directly derived from the work of Porter and Kramer (2006) and Carroll (1979), both of which are grounded in an extensive review of relevant literature; we paid careful attention to developing response options that were meaningful to the managers and were reasonably exclusive and exhaustive within the domain of explicit and implicit CSRs. The initial pool of the 12 items was reviewed and refined in several iterations. To minimize response fatigue and to increase the response rate, we used those items with the highest item-total correlations. This resulted in the selection of eight items-four of which related to explicit CSR and the other four related to implicit CSR. Among these eight statements, respondents were asked to select those SEAs that best described the actions/approaches of their organization in managing stakeholder issues. Appendix A provides the eight items included in the SEA scale designed to measure SEAs.

We assessed the content validity of the items using a panel of organizational behavior and strategy researchers. We tested the scale's predictive validity by correlating an item (not included in the SEA scale) that clearly related to explicit CSR ("My company tries to deal effectively with negative impact of its activities") with the eight items on the SEA scale. This item was both significantly and positively correlated with the items designed to measure explicit CSR, whereas it had a nonsignificant or significant negative correlations with items designed to measure implicit CSR. We repeated the same procedure for assessing the validity of the items designed to measure implicit CSR and correlated another item (not included in the SEA scale) that clearly related to implicit CSR ("My company is aware of the social impacts of its activities"); we obtained similar results in this analysis as well.

\section{4 | Reliability check}

We used a test-retest procedure to assess the reliability of the multiitem scale used to measure the "explicit-implicit CSR." The scale was administered to a pilot sample of 42 participants and then again to the same participants 2 months later. The test-retest reliability coefficient for the multiple options questions ranged from 0.67 to 0.88 , with a mean reliability of.76, which is greater than the generally accepted level of 0.70 (Nunnally, 1978)

\section{5 | RESULTS}

The data collected in this study allowed us to capture the approach that American and Japanese companies took to SEAs approach (explicit vs. implicit). We first generated a correlation matrix to examine the mean and the standard deviation associated with the various items and checked for multicollinearity among variables. The results of the correlation analysis, along with the mean and standard deviation for each variable are presented in Table 1. The results presented in Table 1 show that the means associated with the use of various SEA measures have a large spread (0.18 to 0.62$)$, which is indicative of the variation that exists in the stakeholder management practices of the companies. Results also show that although items related to explicit CSR are positively related to each other, they are either negatively related or have very low co-relation, with items designed to measure implicit CSR.

\section{1 | Factor analysis}

A factor analysis was also conducted in order to identify differences in companies' approaches to managing SEAs. The variables included in the factor analysis referred to the items included in the eight-item SEA scale. We opted to use the direct oblimin method of oblique rotation because there were reasons to believe that there might be a theoretical relationship between the underlying factors. The Kaiser-Meyer-Olkin and Bartlett's test measure of sampling adequacy was used to examine the appropriateness of the factor analysis. The approximate of chi-square is $125.83(p=0.001)$, and the Kaiser-Meyer-Olkin statistic of 0.65 is also large (greater than 0.50 ). Hence, the factor analysis was an appropriate tool for further analysis.

The results of the factor analysis are reported in Table 2. We extracted two factors (each with eigenvalues above the rule of thumb of 1 ), accounting for $41 \%$ of the variance in the research model. The results revealed factor loadings such that three items loaded on first factor, whereas four items loaded on the second factor. Each of these items loaded 0.5 or higher on one factor and 0.3 or lower on the other. 
TABLE 2 Mean, standard deviations, and correlation: Stakeholder management activities (the United States and Japan)

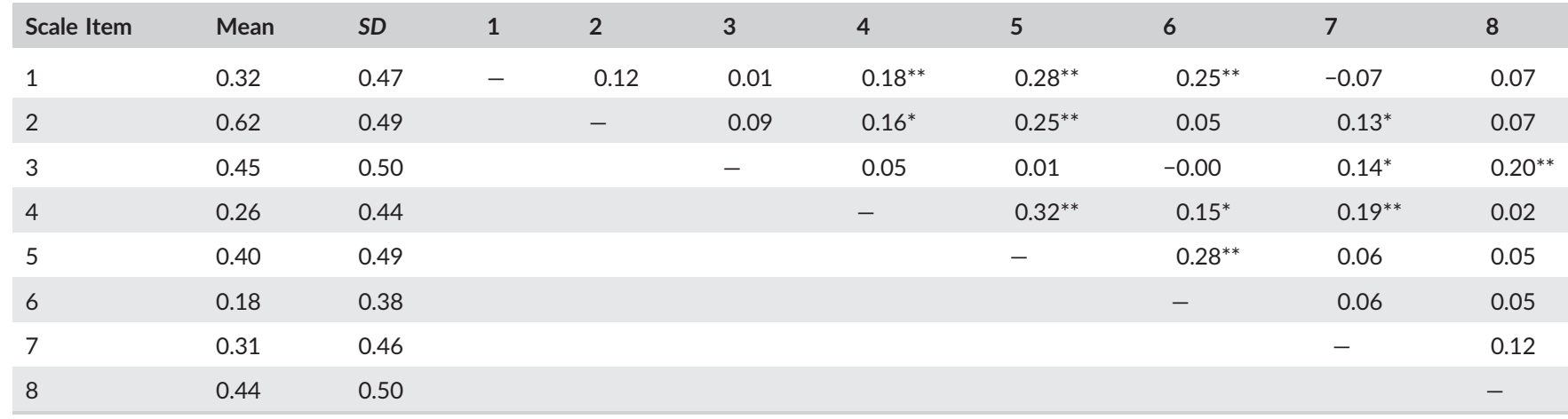

Note. $N=227$.

${ }^{*} p<0.05 .{ }^{* *} p<0.01$.

Only one item ("The stakeholder management efforts of my company are aimed at managing good citizenship image of the company") crossloaded on both factors, despite expecting it to be theoretically linked to implicit CSR. We provide a potential explanation for this unexpected result in Section 6. A close examination of the other seven items included in each of the two factors revealed that scale items in Factor 1 are all related to explicit CSR, whereas scale items in Factor 2 are all related to implicit CSR.

\section{2 | Analysis of variance}

Having validated our SEA scale, we sought to test the core research proposition-that although the CSR activities of the American companies will be characterized by strong explicit CSR, the CSR activities of Japanese companies will exhibit strong implicit CSR. In order to test this, we utilized the two factors that were extracted from the results of factor analysis (which were labelled as explicit CSR and implicit CSR), and using an ANOVA, we examined the difference between the SEAs of the American and Japanese organizations. The results of the ANOVA (reported in Table 3) show a significant difference between American and Japanese organizations in terms of these two factors. As expected, Japanese organizations use stakeholder management activities that are related to implicit CSR significantly more often than American organizations ( $M_{\text {Japan }}=2.25, M_{U S A}=1.36 ; F=39.92$, $p<0.001)$. At the same time, the results show that American organizations use stakeholder management activities that are related to explicit CSR significantly more often than Japanese organizations $\left(M_{\text {USA }}=1.82, M_{\text {Japan }}=1.02 ; F=27.95, p<0.001\right)$.

Finally, to understand the nuanced differences in the SEAs of the American and Japanese companies, we once again relied upon an ANOVA to examine the differences in terms of each individual item included in the two factors-explicit CSR and implicit CSR. The results of the analyses (presented in Table 4) show significant differences between American and Japanese companies in terms of seven of the SEAs. These significant differences provide further evidence that CSR is in fact viewed and practiced differently in these two countries.
TABLE 3 Factor analysis of stakeholder engagement activities: Explicit and implicit CSRs

\begin{tabular}{lcc} 
Scale Item & $\begin{array}{r}\text { Factor 1 } \\
\text { "Explicit } \\
\text { CSR" }\end{array}$ & $\begin{array}{c}\text { Factor 2 } \\
\text { "Implicit } \\
\text { CSR" }\end{array}$ \\
$\begin{array}{l}\text { 1: My company is involved in } \\
\text { constructive dialogue with local } \\
\text { government, regulators, and } \\
\text { community organizations to } \\
\text { identify and support issues that } \\
\text { matter to us. }\end{array}$ & $\underline{0.64}$ & -0.09 \\
\hline
\end{tabular}

2: The stakeholder management
efforts of my company are aimed
at managing good citizenship
image of the company.
conditions.

4: Corporate philanthropy in my
company has clear measurable
goals, and results are tracked
over time.

Cumulative variance

$40.52 \%$

Note. Bold and underlined coefficients load in the factor. 
TABLE 4 Analysis of variance: Differences in the use of explicit and implicit CSR between U.S. and Japanese companies

\begin{tabular}{llllll} 
CSR elements & Country & Mean & SD & F & Sig. \\
\hline \multirow{2}{*}{ Implicit } & Japan & 2.25 & 1.07 & 39.92 & $* * *$ \\
& United States & 1.36 & 1.05 & & \\
\multirow{2}{*}{ Explicit } & Japan & 1.02 & 1.10 & 27.95 & $* * *$ \\
& United States & 1.82 & 1.17 & & \\
\hline
\end{tabular}

Note. $n=119$ (Japan) and $n=108$ (United States). Bold numbers are the highest.

${ }^{* * *} p<0.001$.

In line with our expectations, Japanese companies reported a much higher adoption of SEAs that are associated with implicit CSR, whereas the U.S. companies reported higher adoption of SEAs associated with explicit CSR. It was interesting to note that the item "My company finds ways in course of its business operations to contribute to the advancement of social conditions" that was adopted most (66\%) by the Japanese companies was in fact adopted the least (22\%) by American companies. Similarly, the item, "My company has invested in social aspects in ways that improves its competitiveness," which was adopted by $39 \%$ of American companies, was adopted the least (8\%) by Japanese companies. Such differences highlight somewhat of a contrasting manner in which CSR is approached and practiced in the two countries. An unexpected result was that there was no significant difference in the response to the following SEA item: "The stakeholder management efforts of my companies are aimed at managing good citizenship image of the company." Sixty-eight percent of the Japanese companies and $56 \%$ of the American companies reported the adoption of this item, and the difference between the two groups was not statistically significant. We believe that this may be due to the fact that even though making efforts to manage one's company's image is characteristic of the U.S.-style CSR, showing commitment to generic social issues (like good citizenship) might represent a common value to companies and a requirement, independent of their national context. ${ }^{1}$ As such, we recommend that this item be dropped from the scale in future research (Table 5).

\section{6 | DISCUSSION}

Past research has noted that Japanese businesses promote "corporate conscience-based governance" with shared values of a corporation and its stakeholders (Nakano, 2007; Fukukawa \& Teramoto, 2009). In following such an approach, a company is considered a community in which interests of various participants have to be harmoniously balanced to ensure continued existence and success. We found evidence of this in our data, as $66 \%$ of Japanese respondents reported that their company "... finds ways in course of its business operations to contribute to the advancement of social conditions." This strengthens our position that Japanese companies adopt an implicit CSR approach in which they comply with collectively decided social rules and customary and mandatory obligations in their CSR operations because

${ }^{1}$ The authors would like to thank the anonymous reviewer for this insight. doing good is a societal expectation, not necessarily solely a company's choice.

Japanese companies also focus on the well-being of all their stakeholders, directly or indirectly involved in the company's operations, and do so based upon collective, rather than company-specific deliberations. Once again, such an approach was confirmed by $54 \%$ of the respondents who reported that their "... company's strategy attempts to integrate business and social needs." The implicit CSR approach of Japanese companies is also contextualized by the national business systems of a CME and the social and governmental institutional arrangements associated with CME. As a result, when dealing with issues related to CSR and stakeholder management, Japanese companies are able to balance the interests of various stakeholders through discretion that is reflected in informal and shared understanding of "consensual managerialism" (Kang \& Moon, 2011) rather than formally stated policies. Once again, the fact that nearly half the Japanese companies reported that their company "... attempts to incorporate operational issues that will create social impact to its business decisions" bears evidence to this approach. Based on these findings, it appears reasonable to conclude that Japanese businesses approach CSR in an implicit way and incorporate them into their business practices, without embracing much of the rhetoric typically associated with it.

An interesting, but unexpected, finding of the study relates to the fact that $68 \%$ of the Japanese companies (as opposed to $56 \%$ of the $U$. S. companies) reported that the "stakeholder management efforts of my company are aimed at managing good citizenship image of the company." In the modern business world, one possible explanation for this unexpected result, as noted earlier, could be that management of good citizenship reputation might be a generic requirement common to all global companies, independent of the cultural context. Another possible explanation, as observed by other researchers, might have to do with the rather novel adoption of CSR among Japanese companies in the last decade as a result of increased exposure to the global markets (Fukukawa \& Teramoto, 2009; Fukukawa \& Moon, 2004; Brucksch \& Grünschloß, 2009; Demise, 2005).

Given the market-based approach to economic activities, stakeholder management and CSR are viewed by most U.S. companies as a voluntary concept; something they choose to do. Companies largely use their discretion to engage in CSR in an explicit and firm-specific way and are eager to make claims about socially responsible practices and policies. The fact that $54 \%$ of the American respondents reported that their company "takes pride in its positive involvement in community" shows the predominance of company-specific and explicit CSR approach in the United States. Realizing that CSR initiatives result in a positive perception, American companies are also concerned with how their company's performance can be enhanced through CSR and effective stakeholder management. The nature and practice of CSR in the United States are embedded in the system that leaves CSR at the discretion of corporations to identify company-specific opportunities for socially responsible behaviors. As noted earlier, the corporate social policies and programs enacted by each company are voluntary and are motivated by the perceived expectations of different stakeholders of the company. Such an approach was evident by 
TABLE 5 Analysis of variance: Differences in approach (explicit and implicit) to stakeholder engagement activities between the U.S. and Japanese companies

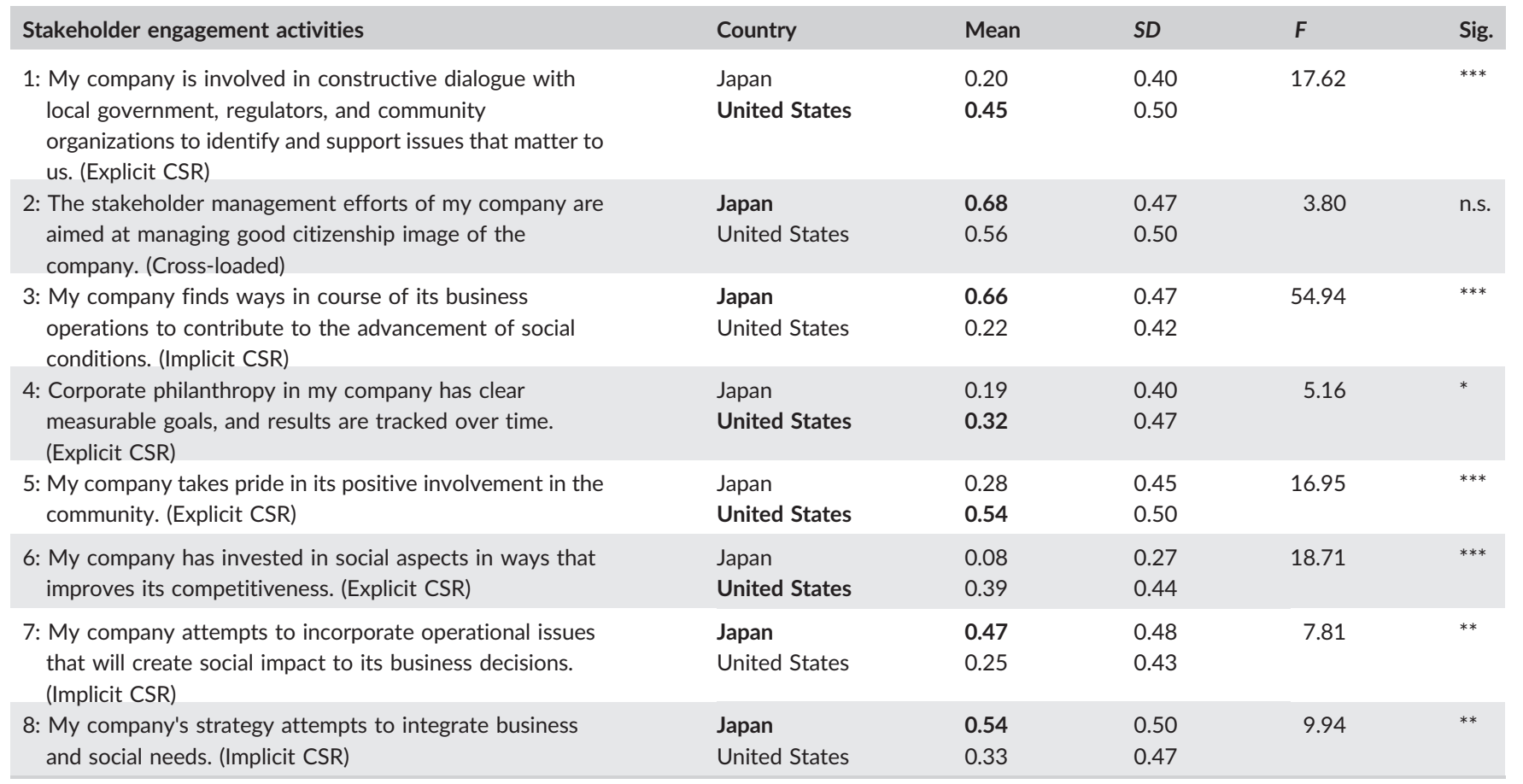

Note. $n=119$ (Japan) and $n=108$ (United States). n.s.: not significant. Bold numbers are the highest.

${ }^{*} p<0.05 .{ }^{* *} p<0.01 .{ }^{* * *} p<0.001$.

the fact that $45 \%$ of the respondents in the United States (as opposed to merely $20 \%$ in Japan) reported that their "... company is involved in constructive dialogue with local government, regulators, and community organizations to identify and support issues that matter to them" and the fact that $31 \%$ more companies in the United States than in Japan reported that their "company has invested in social aspects that improves it competitiveness." These results once again highlight the differences in the way CSR is approached and practiced by companies in the United States and Japan, with the former seemingly using CSR not only for societal benefit but also as a tool for leveraging a competitive benefit.

\section{7 | CONCLUSIONS}

Adding to the existing stream of cross-national CSR research, the present study utilized the institutional theory and comparative capitalism frameworks to explain why the adoption of CSR policies and practices might be different between the United States and Japan and conducted empirical research to find evidence for how the adoption of CSR policies and practices are different between these two countries. By analyzing the responses obtained from the United States and Japanese managers about their companies' approach to CSR and placing this within the broader institutional and national business system contexts that exist in the two countries, we were able to develop a more subtle and, not the least, a more complex understanding of the differences in the prevalence of CSR policies, programs, and practices enacted by the United States and Japanese companies.
Drawing upon the explicit-implicit CSR framework proposed by Matten and Moon (2008), we first developed a SEA scale that allowed us to examine the difference in how companies approach and practice CSR. We proposed that although the approach to the CSR activities of the U.S. companies will be characterized by strong explicit CSR, the approach to CSR activities of Japanese companies will exhibit strong implicit CSR. The results of the study provided strong support for our research proposition. However, the results also provided some indication of a changing balance of implicit and explicit CSRs in case of Japanese companies, which appear to be adopting explicit CSR approach in managing company reputation.

\section{I MANAGERIAL IMPLICATIONS}

The findings of this study have some important implications for practitioners and managers. First, one needs to realize that despite the global nature of CSR, it is conceived, interpreted, and acted upon differently across different social, economic, and business contexts. Companies operating in different countries are contextualized by their national institutional frameworks and economic and social policy arrangements, which create different opportunities and incentives, and hence lead to different approaches to the issues associated with CSR. Furthermore, even though companies in different countries may have CSR policies and programs that appear similar in terms of expected results, they may be approached differently and reported differently. Not understanding these differences can lead one to naively assume that a certain country may somehow be lagging behind 
in CSR, as has been assumed by some in case of the differences that exist between the United States and Japan. The reality may not be a "lag" per se but a difference in the cultural motivation to institutionalize and vocalize CSR efforts. As more and more companies expand operations overseas, there is an increased need to realize these differences, so that the CSR programs and policies of the company are conceived, approached, and acted upon in ways that are appropriate to the prevailing contexts.

\section{I IMPLICATIONS FOR FUTURE RESEARCH}

As noted at the beginning of this study, although existing research provides rich descriptions of the cross-cultural differences in CSR practices, they have not adequately probed these differences within the underlying mechanism of institutional contexts in which companies operate. Similar research needs to be conducted in case of other major countries as well, notably between the United States and other European nations, which, like Japan, are also characterized as CMEs. Also, we investigated the differences in the CSR practices of the United States and Japan based on a single framework-explicit and implicit CSRs. Future researchers could combine more than one framework, such as formal versus informal communication and mandatory versus voluntary issues. Finally, even though we relied exclusively on self-reported measures for this study, supplementing it with archival/publicly available data/information would further enhance the reliability of the findings.

\section{ORCID}

Giacomo Boesso (D) https://orcid.org/0000-0002-7200-7696

\section{REFERENCES}

Aguilera, R. V., \& Jackson, G. (2003). The cross-national diversity of corporate governance: Dimensions and determinants. Academy of Management Review, 28(3), 447-465. https://doi.org/10.5465/amr. 2003.10196772

Aguinis, H., \& Glavas, A. (2012). What we know and don't know about corporate social responsibility: A review and research agenda. Journal of Management, 38(4), 932-968. https://doi.org/10.1177/014920 6311436079

Autodesk, https://www.autodesk.com/retrieved, Dec 15, 2018

Ben-Amar, W., \& Chelli, M. (2018). What drives voluntary disclosure? The effect of country level institutions. Business Strategy and the Environment, 27, 1609-1622. https://doi.org/10.1002/bse.2227

Boesso, G., \& Kumar, K. (2009). Stakeholder prioritization and reporting: Evidence from Italy and the US. Accounting Forum, 33(2), 162-175. https://doi.org/10.1016/j.accfor.2008.07.010

Brucksch, S., \& Grünschloß, C. (2009). From environmental accountability to corporate social responsibility? Reflections on the CSR boom in Japan from the perspective of business management and civil society groups. Japanstudien, 20(1), 307-329. https://doi.org/10.1080/ 09386491.2009 .11826984

Campbell, J. L. (2007). Why would corporations behave in socially responsible ways? An institutional theory of corporate social responsibility. Academy of Management Review, 32(3), 946-967. https://doi.org/ 10.5465/amr.2007.25275684
Carroll, A. B. (1979). A three-dimensional conceptual model of corporate performance. Academy of Management Review, 4(4), 497-505. https://doi.org/10.5465/amr.1979.4498296

Chappel, M., \& Moon, J. (2005). Corporate social responsibility (CSR) in Asia: A seven country study of CSR. Business and Society, 44(4), 415-441. https://doi.org/10.1177/0007650305281658

Choi, J., \& Wang, H. (2009). Stakeholder relations and the persistence of corporate financial performance. Strategic Management Journal, 30(8), 895-907. https://doi.org/10.1002/smj.759

Coombs, J. E., \& Gilley, K. M. (2005). Stakeholder management as a predictor of CEO compensation: Main effects and interactions with financial performance. Strategic Management Journal, 26(9), 827-840. https:// doi.org/10.1002/smj.476

Demise, N. (2005). Business ethics and corporate governance in Japan. Business \& Society, 44(2), 211-217. https://doi.org/10.1177/00076 50305274914

Eweje, G., \& Sakaki, M. (2015). CSR in Japanese companies: Perspectives from managers. Business Strategy and the Environment, 24(7), 678-687. https://doi.org/10.1002/bse.1894

Freeman, I., \& Hasnaoui, A. (2011). The meaning of corporate social responsibility: The vision of four nations. Journal of Business Ethics, 100(3), 419-443. https://doi.org/10.1007/s10551-010-0688-6

Fukukawa, K., \& Moon, J. (2004). A Japanese model of corporate social responsibility? Journal of Corporate Citizenship, 14, 45-49.

Fukukawa, K., \& Teramoto, Y. (2009). Understanding Japanese CSR: The reflections of managers in the field of global operations. Journal of Business Ethics, 85(1), 133-146. https://doi.org/10.1007/s10551-0089933-7

Gjølberg, M. (2009). Measuring the immeasurable? Constructing an index of CSR practices and CSR performance in 20 countries. Scandinavian Journal of Management, 25(1), 10-22. https://doi.org/10.1016/j. scaman.2008.10.003

Graves, S. B., \& Waddock, S. A. (1994). Institutional owners and corporate social performance. Academy of Management Journal, 37(4), 1034-1046.

Hillman, A. J., \& Keim, G. D. (2001). Shareholder value, stakeholder management, and social issues: what's the bottom line? Strategic Management Journal, 22, 125-139. https://doi.org/10.1002/10970266(200101)22:2<125::AID-SMJ150>3.0.CO;2-H

Ho, F. N., Wang, H. M. D., \& Vitell, S. J. (2012). A global analysis of corporate social performance: The effects of cultural and geographic environments. Journal of Business Ethics, 107(4), 423-433. https://doi. org/10.1007/s10551-011-1047-y

Hosoda, M., \& Suzuki, K. (2015). Using management control systems to implement CSR activities: An empirical analysis of 12 Japanese companies. Business Strategy and the Environment, 24(7), 628-642. https:// doi.org/10.1002/bse.1896

Johnson, R. A., \& Greening, D. W. (1999). The effects of corporate governance and institutional ownership types on corporate social performance. Academy of Management Journal, 42(5), 564-576.

Kang, N., \& Moon, J. (2011). Institutional complementarity between corporate governance and corporate social responsibility: A comparative institutional analysis of three capitalisms. Socio-Economic Review, 10(1), 85-108.

Kobayashi, K., Eweje, G., \& Tappin, D. (2018). Employee wellbeing and human sustainability: Perspectives of managers in large Japanese corporations. Business Strategy and the Environment, 27(7), 801-810. https://doi.org/10.1002/bse.2032

Kumar, K., Boesso, G., \& Michelon, G. (2016). How do strengths and weaknesses in corporate social performance across stakeholder domains 
affect company performance. Business Strategy and the Environment, 25(4), 277-292. https://doi.org/10.1002/bse.1874

Kumar, K., Boesso, G., \& Yao, J. (2017). Cultural values, institutional arrangements and stakeholder management culture: A cross-national study. Review of International Business and Strategy, 27(4), 450-465. https://doi.org/10.1108/RIBS-03-2017-0029

Lee, K., Park, B., Song, H., \& Yook, K. (2016). The value relevance of environmental audits: Evidence from Japan. Business Strategy and the Environment, 26(5), 609-625.

Lee, S., Ha-Brookshire, J., \& Chow, P. (2018). The moral responsibility of corporate sustainability as perceived by fashion retail employees: $A$ USA-China cross-cultural comparison study. Business Strategy and the Environment., 27, 1462-1475. https://doi.org/10.1002/bse.2196

Matten, D., \& Moon, J. (2008). "Implicit" and "explicit" CSR: A conceptual framework for a comparative understanding of corporate social responsibility. Academy of Management Review, 33(2), 404-424. https://doi.org/10.5465/amr.2008.31193458

Nakano, C. (2007). The significance and limitations of corporate governance from the perspective of business ethics: Towards the creation of an ethical organizational culture. Asian Business \& Management, 6(2), 163-178. https://doi.org/10.1057/palgrave.abm.9200216

Nunnally, J. (1978). Psychometric methods. NY: McGraw-Hill.

Porter, M. E., \& Kramer, M. R. (2006). Strategy and society: The link between corporate social responsibility and competitive advantage. Harvard Business Review, 84(12), 78-92.
Russo, A., \& Tencati, A. (2009). Formal vs. informal CSR strategies: Evidence from Italian micro, small, medium-sized, and large firms. Journal of Business Ethics, 85, 339-353. https://doi.org/10.1007/s10551008-9736-x

Soskice, D. W., \& Hall, P. A. (2001). Varieties of capitalism: The institutional foundations of comparative advantage. Oxford: Oxford University Press.

Taras, V., Steel, P., \& Kirkman, B. L. (2011). Three decades of research on national culture in the workplace: Do the differences still make a difference? Organizational Dynamics, 40(3), 189-198. https://doi.org/ 10.1016/j.orgdyn.2011.04.006

Tempel, A., \& Walgenbach, P. (2007). Global standardization of organizational forms and management practices? What new institutionalism and the business-systems approach can learn from each other. Journal of Management Studies, 44(1), 1-24. https://doi.org/10.1111/j.14676486.2006.00644.x

Whitley, R. (1998). Internationalization and varieties of capitalism: The limited effects of cross-national coordination of economic activities on the nature of business systems. Review of International Political Economy, 5(3), 445-481. https://doi.org/10.1080/096922998347480

How to cite this article: Kumar K, Boesso G, Batra R, Yao J. Explicit and implicit corporate social responsibility: Differences in the approach to stakeholder engagement activities of U.S. and Japanese companies. Bus Strat Env. 2019;28:1121-1130. https://doi.org/10.1002/bse.2306 